\title{
Immunohistochemical profile of stromal constituents and lymphoid cells over the course of wound healing in murine model ${ }^{1}$
}

\author{
Bernadeth Moda de Almeida', Marismar Fernandes do NascimentoI, Rose Nely Pereira-Filho" ${ }^{\text {II }}$, Genecy Calado de Melo ${ }^{\text {III }}$, José \\ Cleveilton dos Santos ${ }^{\mathrm{III}}$, Clauberto Rodrigues de Oliveira ${ }^{\mathrm{IV}}$, Margarete Zanardo Gomes ${ }^{\mathrm{V}}$, Sônia Oliveira Lima ${ }^{\mathrm{VI}}$, Ricardo Luiz \\ Cavalcanti de Albuquerque-Júnior ${ }^{\mathrm{VII}}$
}

DOI: http://dx.doi.org/10.1590/S0102-8650201400150007

${ }^{\mathrm{I}}$ Fellow PhD degree, Postgraduate Program in Biotechnology (RENORBIO), Tiradentes University (UNIT), Aracaju-SE, Brazil. Technical procedures, manuscript preparation.

IIFellow PhD degree, Postgraduate Program in Biotechnology (RENORBIO), UNIT, Aracaju-SE, Brazil. Acquisition of data.

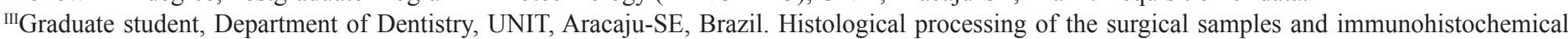
staining.

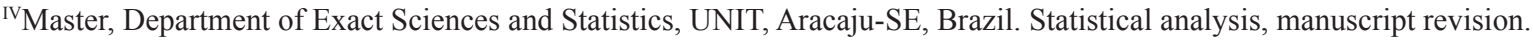

${ }^{v} \mathrm{PhD}$, Laboratory of Morphology and Experimental Pathology, Department of Medicine, UNIT, Aracaju-SE, Brazil. Manuscript writing, critical revision.

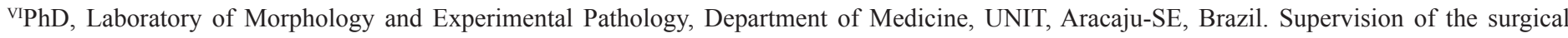
procedures in rodent model.

${ }^{V I I} P h D$, Full Professor, Laboratory of Morphology and Experimental Pathology, Department of Medicine, UNIT, Aracaju-SE, Brazil. Design of the study, supervision of the histological examinations, critical revision.

\footnotetext{
ABSTRACT

PURPOSE: To assess the evolution profile of the immunohistochemical expression of stromal constituents over the time-course of wound healing in a murine model.

METHODS: Surgical wounds were performed in the back of 24 Wistar rats. After three, seven, 14 and 21 days, six rats were euthanized and the wounded histologically processed to assess the immunohistochemical expression of CD3, CD20, CD31, $\alpha$-SMA and type-I collagen. Non-injured skin samples (NSS) were used as control. Data were subjected to statistical analysis using ANOVA and Tukey test.

RESULTS: The mean of CD3 and CD20 positive cells in the wounds was significantly higher than in NSS at seven and 14 days $(\mathrm{p}<0.001)$. The blood vessels content was significantly lower than in NSS $(p<0.05)$ at three days, but increased at seven and 14 days $(\mathrm{p}<0.01)$. The mean of $\alpha$-SMA positive cells at seven, 14 and 21 days was higher than in NSS $(p<0.05)$. The relative content of type I collagen increased from three to 21 days, but remained lower than in NSS ( $<<0.05)$.

CONCLUSIONS: Lymphoid cells, myofibroblasts and microvessels contents varied over the time-course of wound healing, with peak at seven days and progressive reduction until 21 days. The type I collagen content increased over time.

Key words: Wound Healing. Immunohistochemistry. Histological Techniques. Rats, Wistar.
} 


\section{Introduction}

The major function of skin is to provide a protective barrier against the environment. The loss of integrity due to surgery, trauma, ischemia, burns, long-term high pressure or any other sort of external aggression can alter the morphological and functional skin conditions resulting in tissue injury or wound ${ }^{1}$.

It has been reported that partial thickness wounds are supposed to heal by mere epithelialization, whereas the healing of full thickness wound involves more complex wellregulated biological events, including the inflammatory response, granulation tissue formation, myofibroblastic differentiation and collagenization $^{2,3}$. This process is directly or indirectly responsible or eliminating the bacterial load, removing necrotic debris, inducing wound contraction and stimulating the scar formation. The use of simple and reproducible models is a fundamental requirement for objective assessment of the effects of a wide range of external factors on the different steps of wound healing, i.e. inflammation, proliferation, and remodeling phases ${ }^{4}$.

Several studies have been performed in order to search for new therapeutic approaches to improve wound healing ${ }^{3,5}$. Such studies have used histochemical and/or immunohistochemical methods to investigate the morphological changes that occur during the healing process of injured dermal tissues. However, there are only some few papers looking at the assessment and analysis of the histological features of stromal and inflammatory profile over the time-course of the spontaneous scar tissue formation ${ }^{6}$.

Thus, the goal of this study was to assess immunohistochemical profile of stromal constituents and lymphoid cells over the time-course of wound healing in a murine model. With this study, we aim to provide more objective data about the relations between the histological changes and the evolution stage of wound healing.

\section{Methods}

All the procedures for animal research were performed in accordance with the guideline of the Brazilian Council for Animal Experimentation and followed a protocol approved by the Animal Ethics Committee of Tiradentes University (approval subscription $\mathrm{n}^{\mathrm{o}}$ 101112).

Twenty-four male Rattus norvegicus albinus, Wistar lineage, $(300 \pm 20 \mathrm{~g}$ weight) were obtained from Animal Facility of Tiradentes University (Sergipe, Brazil). The rats were housed in clear plastic cages with solid floors and loose hardwood chip bedding, and supplied with food and water ad libitum and maintained under controlled temperature $\left(25 \pm 2^{\circ} \mathrm{C}\right)$ and relative humidity $(50 \pm 5 \%)$, with a $12 \mathrm{~h}$ light/dark cycle.

\section{Biological assay}

The rats were anesthetized with intraperitoneal ketaminexylazine $(100 \mathrm{mg} / \mathrm{kg}-5 \mathrm{mg} / \mathrm{kg})$ and one full-thickness round-shaped wound was performed on the back (in the middle, on the spine, $1 \mathrm{~cm}$ under the interescapular area) of each animal using an $8 \mathrm{~mm}$ biopsy punch. The animals were assigned into four groups $(n=6)$, according to the time of euthanize, which was carried out three, seven, 14 and 21 days after the surgical procedures. The euthanize was performed in $\mathrm{CO}_{2}$ chamber (EB 248, 400 x 320 x 350 mm, Insight, Sao Paulo, Brazil) with $100 \%$ carbon dioxide continuous flux for $5 \mathrm{~min}$. After death certification, the wounded areas were removed, formalin-fixed and paraffin-embedded. Histological sections, serial, of $5 \mu \mathrm{m}$ thick, were obtained and stained by immunohistochemical techniques.

\section{Immunohistochemical assay}

Immunohistochemical staining was performed through the indirect biotin streptoavidin method using the DAB Detection Kit (Ventana Medical Systems, Tucson, AZ, USA). The sections were deparaffinized in xylene and were sequentially washed twice in $100 \%$ alcohol and in $95 \%, 90 \%, 80 \%$, and $70 \%$ alcohol for 2 min. To increase the antigen detection, the slides were immersed in a citrate acid solution and were heated in a microwave for $20 \mathrm{~min}$. The cells/ collagen-specific antigens staining were performed with primary antibodies as described in Table 1. After the slides were incubated with streptavidin-biotin-peroxidase complex (Dako, K069011-2, Sao Paulo, Brazil) for $30 \mathrm{~min}$. at room temperature. Subsequently, the slides were exposed to Diaminobenzidine (DAB, Ventana Medical Systems, Tucson, AZ, USA) for four minutes and were counterstained with Mayer's Hematoxylene for four minutes. For a negative control, nonimmune mouse serum IgG was used instead of primary antibodies.

TABLE 1 - Primary antibodies used in the immunohistochemical assay.

\begin{tabular}{|c|c|c|c|c|}
\hline Antibody & Clone & Company & Dilution & Specificity \\
\hline $\begin{array}{l}\text { Anti-type I } \\
\text { collagen }\end{array}$ & AB34710 & Abcam & $1: 100$ & Type I collagen \\
\hline Anti- $\alpha-S M A$ & $1 \mathrm{~A} 4$ & Dako & $1: 20$ & Myofibroblasts \\
\hline Anti-CD31 & $\mathrm{JC} / 70$ & Dako & $1: 20$ & Endothelial cells \\
\hline AntiCD3 & UCHT & Dako & $1: 100$ & $\begin{array}{c}\text { T cells } \\
\text { (lymphocytes) }\end{array}$ \\
\hline Anti-CD20 & L26 & Dako & $1: 150$ & $\begin{array}{c}\text { B cells } \\
\text { (lymphocytes) }\end{array}$ \\
\hline
\end{tabular}




\section{Immunohistochemical analysis}

Ten histological sections ( $\mathrm{x} 40,10$ ocular, $0.739 \mathrm{~mm}^{2}$ per field) were randomly selected and the mean of immunostained cells (positive for anti- $\alpha-S M A, C D 3$ and CD20 antibodies) was assessed with an image analysis system Imagelab ${ }^{\circledR}$ (Softium, Sao Paulo-SP, Brasil). To assess the mean number of microvessels, the same procedure was carried out counting the capillary vessels formed by CD31-positive endothelial cells. The quantitative analysis of the content of Type-I collagen fibers in the healing area was determined by optical density in the image analysis system in different randomly selected fields. The system used consists of a CCD Sony DXC-101 camera, applied to an Olympus CX31 microscope, from which the images were sent to a monitor (Trinitron Sony). Using a digitizing system (Olympus C-7070 WIDEZOOM) the images were inserted into a computer (Pentium $133 \mathrm{MHz}$ ), and processed by a software (ImageLab, Sao Paulo, Brazil). A total of ten fields per case were analyzed at a magnification of $x 100$. The thresholds for collagen fibers were established for each slide, after enhancing the contrast up to a point at which the fibers were easily identified as stained collagen bands. The area occupied by the fibers was determined by digital densitometric recognition, by adjusting the threshold level of measurement up to the different color densities of the collagen fibers. The area occupied by the fibers was divided by the total area of the field. The results were expressed in percentage of the skin area fraction occupied by the collagen fibers

\section{Statistical analysis}

Statistical significance of the quantitative measurement was assessed by analysis of variance (one-way ANOVA) and Tukey test. Two-tailed a-levels of $p<0.05$ were regarded as significant difference.

\section{Results}

As demonstrated in Figure 1a and 2a, CD3 and CD20 antigens were found to be positive in uniform populations of small cells, round in shape with scant but well-defined cytoplasm and dark centrally placed nuclei, consistent with lymphocytes. At three days, the small amount of both CD3 and CD20 positive cells were concentrated in the bottom and edges of the wounds. The content of CD3 and CD20 positive cells is shown in Figure $1 \mathrm{~b}$ and $2 \mathrm{~b}$, and presented a similar behavior. It was still inconspicuous and statistically similar to the NSS ( $>0.05)$ at three days. The mean of both cell subsets increased significantly and reached the peak at seven days, and then decreased progressively untill 21 days. Only at seven and 14 days the lymphoid infiltrate was significantly higher than in NSS $(\mathrm{p}<0.001)$. The content of CD3 positive cells was significantly higher than the CD20 positive cells at both seven $(\mathrm{p}<0.001)$ and 14 days $(\mathrm{p}<0.001)$ (Figure 2$)$.
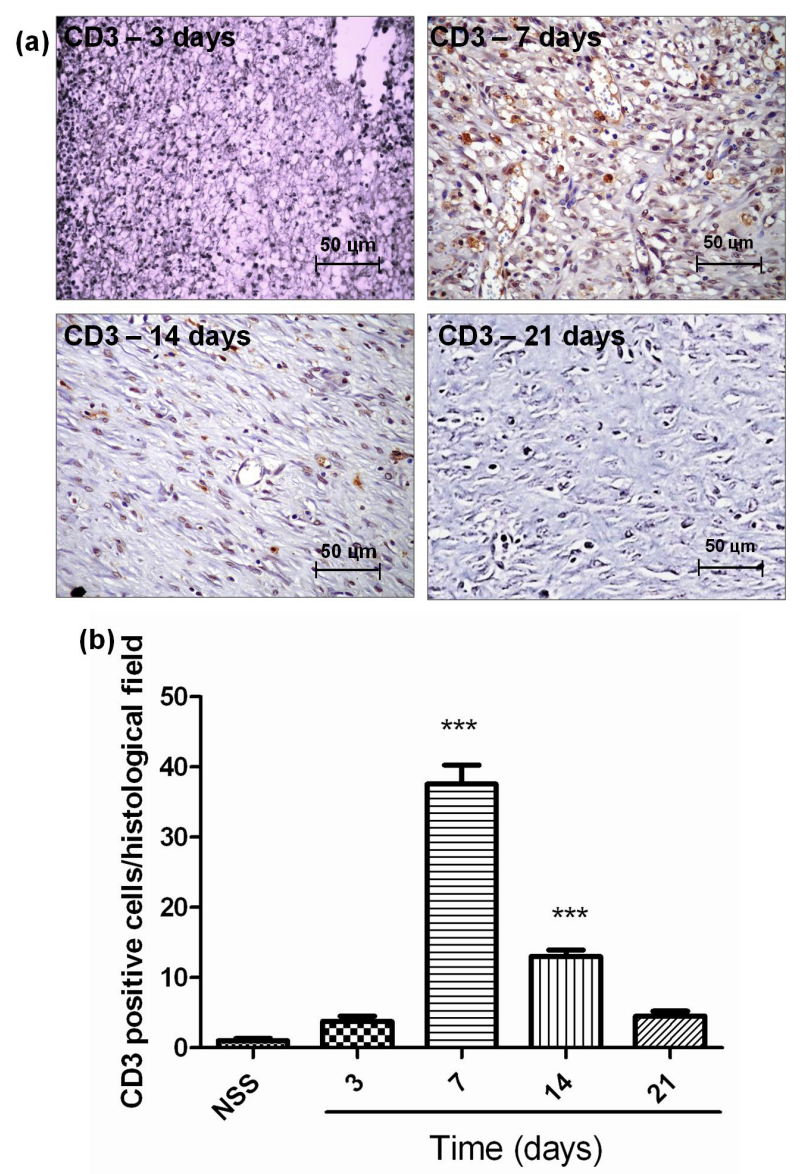

FIGURE 1 - (a) CD3 positive lymphoid cells showing cytoplasmic immunostaining pattern and (b) quantitative analysis of CD3 positive cells per histological field (x400 magnification) over the time course of the experiment. Data were expressed as mean \pm SEM. (*** $p<0.001-$ statistically different from NSS - Non-injured Skin Sample, according to ANOVA and Tukey test). 
(a)

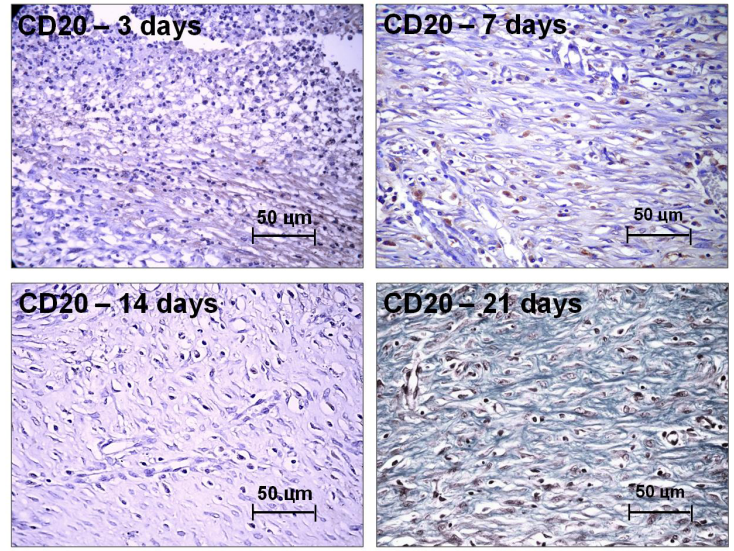

(b) 흥

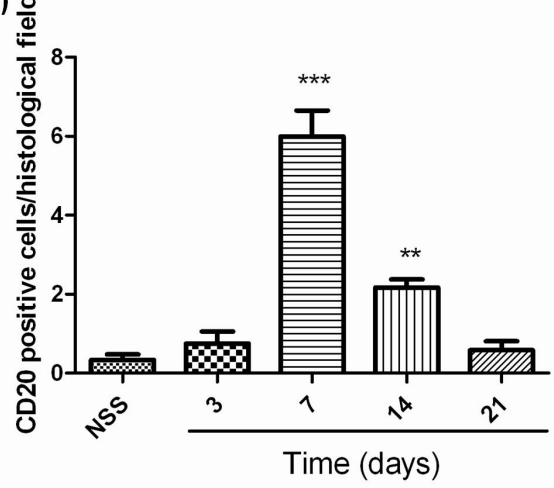

FIGURE 2 - (a) CD20 positive lymphoid cells showing cytoplasmic immunostaining pattern and (b) quantitative analysis of CD20 positive cells per histological field (x400 magnification) over the time course of the experiment. Data were expressed as mean \pm SEM. (*** $p<0.001$; $++p<0.01$ - statistically different from NSS - Non-injured Skin Sample, according to ANOVA and Tukey test).

Positivity for CD31 antigen was observed in the cytoplasm of spindle-shaped cells either forming small vascular spaces or proliferating in the connective tissue, which was compatible with endothelial cells (Figure 3a). As shown in Figure $3 \mathrm{~b}$, at three days, the content of blood vessels $(0.40 \pm 0.22)$ was significantly lower than in NSS $(1.60 \pm 0.22)(\mathrm{p}<0.05)$ and then increased significantly, reaching the peak of neovascularization at seven days $(20.70 \pm 1.35)(\mathrm{p}<0.001)$. At 14 days, the mean of blood vessels decreased in relation to seven days $(9.50 \pm 1.04)$ $(\mathrm{p}<0.01)$, but remained significantly higher than NSS $(\mathrm{p}<0.001)$. At 21 days, the content of blood vessels counted in the scarring area $(2.40 \pm 0.71)$ was similar to that observed in NSS ( $p>0.05)$. (a)
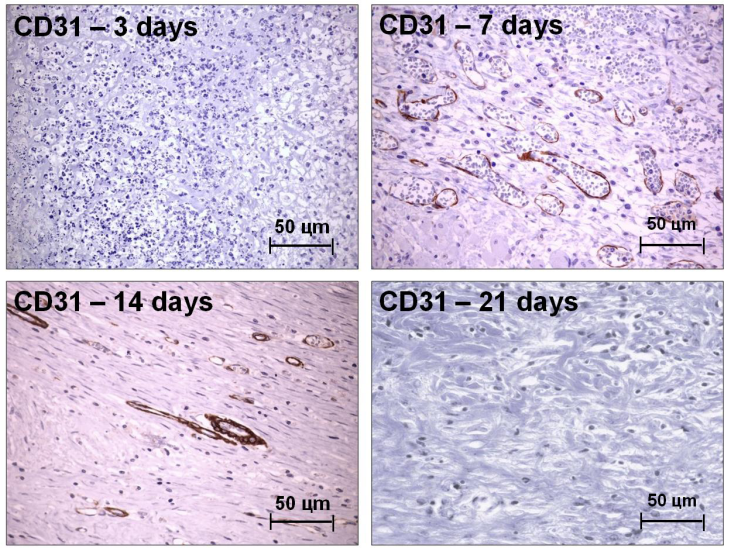

(b) 흥

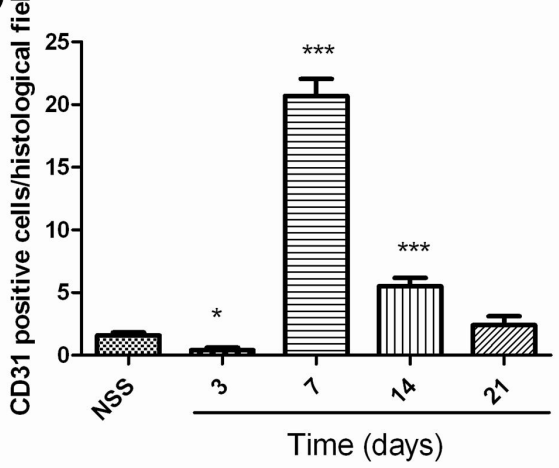

FIGURE 3 - (a) CD3 positive endothelial cells showing cytoplasmic immunostaining pattern in spindle-shaped cells either forming small vascular spaces or spread throughout the connective tissue and (b) quantitative analysis of CD31 positive cells per histological field (x400 magnification) over the time course of the experiment. Data were expressed as mean \pm SEM. (*** $\mathrm{p}<0.001$ - statistically different from NSS - Non-injured Skin Sample, according to ANOVA and Tukey test).

The $\alpha$-SMA antigen was also positive in spindleshaped cells scattered in the wounded area, following the orientation of collagen bundles, interpreted as myofibroblasts. The immunoexpression of $\alpha$-SMA in cells surrounding capillary vessels was regarded as pericytes rather than myofibroblasts (Figure 4a). The Immunohistochemical expression of myofibroblasts ( $\alpha$-SMA positive cells) in NSS $(0.91 \pm 0.33)$ was similar to that observed at three days $(1.0 \pm 0.32)(\mathrm{p}>0.05)$. At seven days, the myofibroblasts differentiation increased significantly (31.78 \pm 4.75$)$ and then decreased progressively at $14(15.50 \pm 1.39)$ and 21 days (4.83 \pm 0.88$)$. The mean of myofibroblasts at seven, 14 and 21 days was significantly higher than NSS $(\mathrm{p}<0.001, \mathrm{p}<0.001$ and $\mathrm{p}<0.05$, respectively). In addition, the highest peak of myofibroblast was observed at seven days, and it was significantly higher than at all the experimental times $(\mathrm{p}<0.001)$ (Figure $4 \mathrm{~b})$. 
(a)

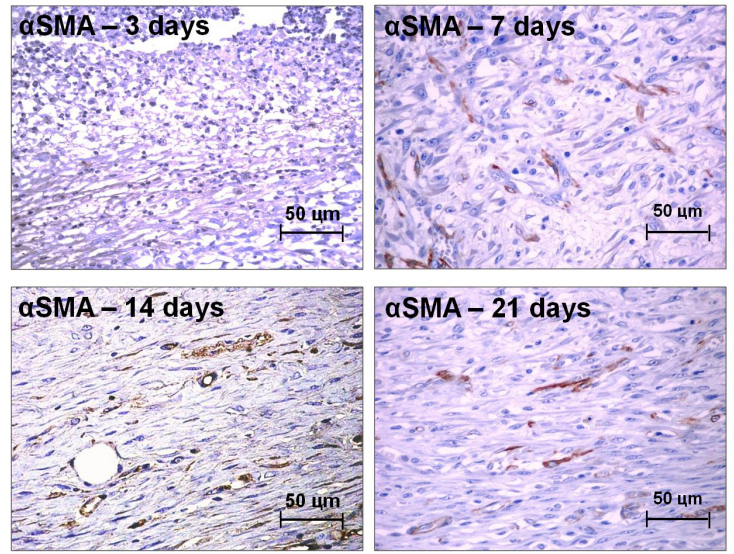

(b) 흥

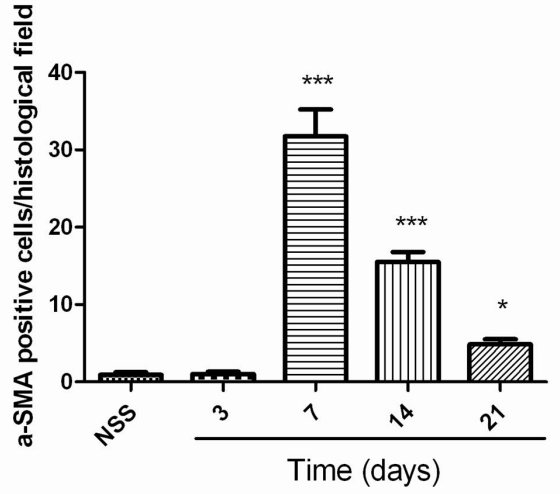

FIGURE 4 - (a) $\alpha$-SMA positive cells showing cytoplasmic immunostaining pattern in spindle-shaped myofibroblastic cells and (b) quantitative analysis of $\alpha$-SMA positive cells per histological field (x400 magnification) over the time course of the experiment. Data were expressed as mean \pm SEM. $(* * * p<0.001 ; * p<0.05$ - statistically different from NSS - Non-injured Skin Sample, according to ANOVA and Tukey test).

Type I collagen immunostaining was light and sparse, with an uneven distribution, at the first phases of wound healing, but thick and heavy, with a widely distributed staining pattern, at the final phases (Figure 5a). The relative content of type I collagen in NSS $(88.67 \pm 1.53)$ was significantly higher than the ones observed in the scarring area at three $(8.35 \pm 0.95)(\mathrm{p}<0.001)$, seven $(23.32 \pm 1.91)(p<0.001), 14(42.88 \pm 2.74)(p<0.001)$ and 21 days $(78.81 \pm 2.71)(\mathrm{p}<0.05)$. The lowest relative content of type I collagen was observed at three days, which increased progressively until 21 days (Figure 5b). (a)
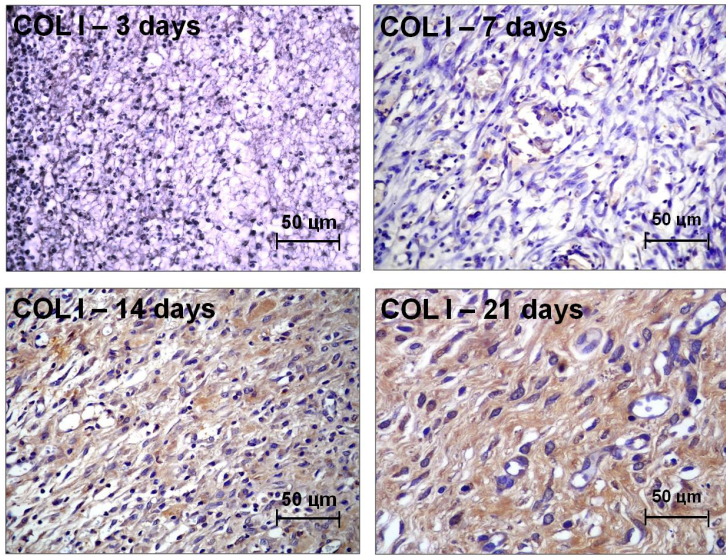

(b) $\frac{\bar{\tau}}{2}$

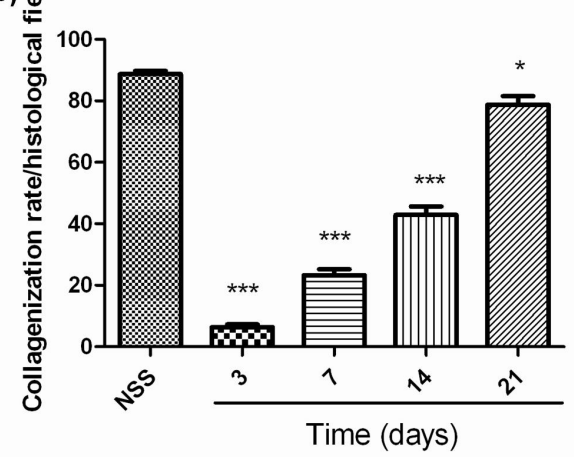

FIGURE 5 - (a) Immunostaining pattern of type I collagen fibers in the connective tissue and (b) quantitative analysis of the collagen density rate per histological field (x400 magnification) over the time course of the experiment. Data were expressed as mean \pm SEM. $\left({ }^{* * *} p<0.001 ;{ }^{*} p<0.05\right.$ - statistically different from NSS - Non-injured Skin Sample, according to ANOVA and Tukey test).

\section{Discussion}

The inflammatory response is regarded as one of the major physiopathologic events associated wuth the wound healing dynamics. At early stages, such biological process is characterized by intense influx of polymorphonuclear neutrophils, which are subsequently replaced by macrophages and lymphocytes (chronic inflammation) and newly formed capillary blood vesses, representing the granulation tissue. At latter stages of wound healing, this vessels-rich tissue is replaced by a collagenous connective tissue, representing the fibrous scar ${ }^{7}$. It has been reported that the immunohistochemical analysis of the inflammatory profile, particularly the lymphoid cells, might be useful to evaluate the evolutive dynamic of wound healing ${ }^{5,6}$.

CD3 antigen is a transmembrane protein complex widely expressed in $\mathrm{T}$ cells. Previous studies have demonstrated the identification of $\mathrm{T}$ cells in samples of mouse skin in wound healing experiments using the immunohistochemical detection of $\mathrm{CD} 3$ antigen 5 . On the other hand, CD20 antigen is an activated-glycosylated 
phosphoprotein express in the membrane surface of $\mathrm{B}$ cells ${ }^{8}$. In this study, the behavior presented by $\mathrm{T}$ and $\mathrm{B}$ cells over the course of wound healing was similar to those reported by Ribeiro et al..$^{5}$. The lack of substantial lymphocyte infiltrate at three days is likely related to the acute phase of the inflammatory response, maunly composed of polymorphonuclear neutrophils ${ }^{3}$. The peak of lymphocytes infiltrate observed in seven days might have occurred as a response to active antigens presentation in peripheral lymphoid tissues, leading to consequent proliferation, migration and accumulation of these cell subsets at the injury site. The relevance of this finding lies in the fact that lymphocytes, particularly $\mathrm{T}$ cells, are one of the major sources of cytokines widely required to the progression of the healing process, such as interleukin-2 (IL-2) and insulin-like growth factor $(\mathrm{IGF})^{9}$, as well as macrophage activator factor (MAF), chemokines and endothelial proliferation stimulator cytokines ${ }^{10}$. However, the function of B cells in wound healing is still unclear, but a possible role in the production of growth factors, e.g. fibroblast growth factor (FGF), platelet-derived growth factor (PDGF) and transforming growth factor- $\beta$ (TGF- $\beta$ ), has been postulated ${ }^{11}$. Subsequent gradual decrease in the lymphocyte content appears to be related to the progressive elimination of phlogistic bacterial-derived products and necrotic debris, thus reducing the antigen presentation and lymphocyte activation $^{12}$. Furthermore, the reduction of lymphocyte content at 21 days to the same levels observed in non-injured skin samples suggests that the healing process advanced to the fibrous remodeling phase, where the chronic phase of the inflammatory response has already been dissipated ${ }^{3}$.

CD31 is a $130 \mathrm{kDa}$ transmembrane glycoprotein found in intercellular junctions of endothelial cells and the immunodetection of this antigen has been used to identify endothelial cells in experimental models ${ }^{13}$. Angiogenesis displays an essential role in wound healing, since the blood vessels content is the major component of the granulation tissue, which grants the nutrients and oxygen supply required to the reconstitution of the injured tissue ${ }^{7}$. In this study, The pattern of immunohistochemical expression of CD31 observed in this study, with a peak at seven days and gradual decrease until 21 days. Thus, the increased number of CD31-positive endothelial cells is related to the development of the granulation tissue, and its decrease of the time course of the experiment is likely associated with the progressive replacement of the granulation tissue by the fibrous scar. The precise mechanisms underlying such increase in endothelial cells and capillary blood vessels remains unclear, but it has been suggested that the accumulation of pro-angiogenesis growth factors derived from lymphoid and stromal cells, such as FGF $\beta$, TGF $\beta$, PDGF e VEGF, might be responsible for this biological effect ${ }^{14}$. In fact, the Immunolabeling patterns of lymphoid cells observed in this study appears to support this theory. Furthermore, the long-term persistence of a relatively high content of blood vessels until 21 days seems to suggest that, although it is advanced, the healing process is still ongoing and not fully established.

Myofibroblasts are an intermediate cell type between fibroblasts and smooth muscle cells responsible for meeting the temporarily high demand for contractile cells in wound repair ${ }^{15}$. Myofibroblasts express $\alpha$-SMA, an early differentiation marker of vascular smooth muscle cells, that confers to them a twofold stronger contractile activity compared with $\alpha$-SMA-negative fibroblasts in culture ${ }^{16}$. The major source of myofibroblasts in skin wounds is the fibroblasts recruited from dermis and subcutaneous tissues surrounding the wound, but pericytes and vascular smooth muscle cells are also potential able to differentiate into myofibroblasts ${ }^{15,16}$. In this study, the immunohistochemical expression of $\alpha$-SMA in stromal cells permeating collagen fibers was interpreted as positive markers of myofibroblasts, whereas stained cells surround blood vessels was considered consist with pericytes and then discarded. We found a peak of myofibroblast differentiation at seven days, with progressive decrease over 14 and 21 days, and a similar pattern was also reported in many other previous studies ${ }^{2,5}$. It has been reported that the higher rate of fibroblasts differentiation into myofibroblasts at this experimental time is likely related to at least three biological events that typically occurs during the granulation tissue phase of wound healing are required to promote the differentiation of fibroblasts into myofibroblasts: accumulation of transforming growth factor $\beta 1$ (TGF$\beta 1$ ), the presence of specialized extracellular matrix (ECM) proteins, such as the ED-A splice variant of fibronectin; and high extracellular mechanical stress of the ECM and cell remodeling activity ${ }^{16}$. On the other hand, further reduction of myofibroblasts number seems to occur in response to apoptosis mediated by progressive decrease in local levels of TGF- $\beta^{16}$. Studies have demonstrated that myofibroblasts are essential to wound healing since there is a direct correlation between the wound tension strength, as well as wound contraction rates, and myofibroblasts differentiation ${ }^{15}$.

Type I collagen is the major extracellular matrix compound of the dermal and mucosal connective tissues and it is fundamental to ensure the optimal mechanical properties of the healing scar. Such biological activity depends on the optimal organization and interaction between collagen fibrils as well as between fibers ${ }^{17}$. In the current studym the quantitative analysis of the immunohistochemical expression of type I collagen, over the time-course of wound healing showed progressive collagenization occurring from three to 21 days, but even at the end of the experimental period, it remained lower in comparison with the non-injured dermal tissues. In accordance with 
our data, several studies have also reported the same collagenization profile in wound healing experimental models ${ }^{3,18}$. At earlier phases, type I collagen fibers are scanty, thin, delicate and parallel-arranged, but as long as the healing process evolutes, the fibers become gross, thick, and display an interlaced arrangement. Such changes in the density and architectural organization of the collagen fibers likely occur to provide improvement of the tensile strength of the wounds. Supporting this theory, it has been previously reported that about 3\% of the intact skin resistance is restored at the end of the first week after the tissue injury, increasing to $30 \%$ at the third week and $90 \%$ after three months ${ }^{19}$. In approximately one year, the type I collagen content is quite close to that observed in non-injured skin, but the wound will never reach $100 \%$ of their physiological resistance of the normal dermal tissues ${ }^{20}$.

\section{Conclusion}

Lymphoid cells, myofibroblasts and microvessels contents varied over the time-course of wound healing, with peak at seven days and progressive reduction until 21 days. The type I collagen content increased over time.

\section{References}

1. Stephen-Haynes J. The outcomes of barrier protection in periwound skin and stoma care. Br J Nurs. 2014 Mar;23(5):26-30. PMID: 24642771 .

2. Almeida EB, Cardoso JC, Lima AK, Oliveira NL, Pontes-Filho NT, Lima SO, Souza ICL, Albuquerque RLC Jr. The incorporation of Brazilian propolis in to collagen-based dressing films improves dermal burn healing. J Ethnopharmacol. 2013 May;147(2): 41925. doi: 10.1016/j.jep.2013.03.031.

3. Barreto RSS, Albuquerque RLC Jr, Pereira-Filho RN, Quintans JSS, Barreto AS, DeSantana JM, Santana-Filho VJ, Santos, MRV, Bonjardim, LR, Araújo, AAS, Quintans LJ Jr. Evaluation of wound healing activity of atranorin, a lichen secondary metabolite, on rodents. Rev Bras Farmacogn. 2013 Mar./Apr;23(2): 310-19. doi: 10.1590/S0102-695X2013005000010.

4. Dorsett-Martin WA. Rat models of skin wound healing: a review. Wound Repair Regen. 2004 Nov-Dec;12(6):591-9. PMID: 15555049.

5. Ribeiro MA, Albuquerque RLC Jr, Ramalho LM, Pinheiro AL, Bonjardim LR, Da Cunha SS. Immunohistochemical assessment of myofibroblasts and lymphoid cells during wound healing in rats subjected to laser photobiomodulation at $660 \mathrm{~nm}$. Photomed Laser Surg. 2009 Feb;27(1):49-55. doi: 10.1089/pho.2007.2215.

6. Sabol F, Bancakova L, Gal P, Vasilenko T, Novorny N, Smetana K, Lenhardt L. Immunohistological changes in skin wounds during the earlier periods of healing in a rat model. Vet Med. 2012;57(2):77-82.

7. Diegelmann, RF, Evans C M. Wound healing an overview of acute, fibrotic and delayed healing. Front Biosci. 2004 Jan;9(1): 283-9. PMID: 14766366.

8. Chetty R, Gatter K. CD3: Structure, function, and role of immunostaining in clinical practice. J Pathol. 1994 Aug; 173(4):3037. PMID: 7525907.
9. Toulon A, Breton L, Taylor KR, Tenenhaus M, Bhavsar D, Lanigan C, Rudolph R, Jameson J, Havran WL. A role for human skinresident T cells in wound healing. J Exp Med. 2009 Apr;206(4):74350. doi: 10.1084/jem.20081787.

10. Mendonça RJ, Netto JC. Aspectos celulares da cicatrização. An Bras Dermatol. 2009 Jul;84(3): 257-62. doi:10.1590/S036505962009000300007.

11. Iwata Y, Yoshizaki A, Komura K, Shimizu K, Ogawa F, Hara T, Muroi E, Bae S, Takenaka M, Yukami T, Hasegawa M, Fujimoto M, Tomita Y, Tedder TF, Sato S. CD19, a response regulator of B lymphocytes, regulates wound healing through hyaluronan-induced TLR4 signaling. Am J Pathol. 2009 Aug; 175(2):649-60. doi: 10.2353/ajpath.2009.080355.

12. Boyce DE, Jones WD, Ruge F, Harding KG, Moore K. The role of lymphocytes in human dermal wound healing. Br J Dermatol. 2000 Jul;143(1):59-65. PMID: 10886136.

13. Melo VA, Anjos DC, Albuquerque R Jr, Melo DB, Carvalho FU. Effect of low level laser on sutured wound healing in rats. Acta Cir Bras. 2011 Apr; 26(2):129-34. doi: 10.1590/S010286502011000200010.

14. Tonnesen MG, Feng X, Clark RA. Angiogenesis in wound healing. J Investig Dermatol Symp Proc. 2000 Dec;5(1):40-6. doi: 10.1046/j.10870024. 2000.00014.

15. Li B, Wang JH. Fibroblasts and myofibroblasts in wound healing: force generation and measurement. J Tissue Viability. 2011 Nov;20(4): 108-20. doi: 10.1016/j.jtv.2009.11. 004.

16. Hinz B. The myofibroblast: paradigm for a mechanically active cell. J Biomech. 2010 Jan;43(1):146-55. doi: 10.1016/j. jbiomech.2009.09.020.

17. Tettamanti G1, Grimaldi A, Congiu T, Perletti G, Raspanti M, Valvassori R, de Eguileor M. Collagen reorganization in leech wound healing. Biol Cell. 2005 Jul;97(7):557-68. doi: 10.1042/BC20040085.

18. Townsend CM, Beauchamp D, Evers M, Mattox KL. Sabiston textbook of surgery. St Louis: Elsevier; 2011.

19. Broughton G 2nd, Janis JE, Attinger CE. The basic science of wound healing. Plast Reconstr Surg. 2006 Jun; 117(7):12-34. doi: 10.1097/01.prs.0000225430. 42531.c2.

20. Li J, Chen J, Kirsner R. Pathophysiology of acute wound healing. Clin Dermatol. 2007 Jan-Feb;25(1):9-18. doi: 10.1016/j. clindermatol.2006.09.007.

\section{Correspondence:}

Ricardo Luiz Cavalcanti de Albuquerque-Júnior

Laboratório de Morfologia e Patologia Experimental

Instituto de Tecnologia e Pesquisa, Universidade Tiradentes

Avenida Murilo Dantas, 300

49032-490 Aracajú - SE Brasil

Tel.: (55 79)3218-2190/ramal 2615

ricardo.patologia@uol.com.br

Received: Apr 17, 2014

Review: Jun 16, 2014

Accepted: July 18, 2014

Conflict of interest: none

Financial sources: Foundation for Research and Technological Innovation Support from Sergipe (FAPITEC/SE) and Brazilian Bureau of Research

${ }^{1}$ Research performed at Laboratory of Morphology and Experimental Pathology (LMBE), ITP (Science and Technology Institute), Tiradentes University (UNIT), Aracaju-SE, Brazil. 